1Fundação Oswaldo Cruz (Fiocruz), Escola Nacional de Saúde Pública Sergio Arouca (Ensp) - Rio de Janeiro (RJ), Brasil. rafaelafacchettiensp. fiocruz.br

2 Defensoria Pública do Estado do Rio de Janeiro Rio de Janeiro (RJ), Brasil. Universidade Federal do Rio de Janeiro (UFRJ) - Rio de Janeiro (RJ), Brasil. elidaseguin@gmail.com

3 Fundação Oswaldo Cruz (Fiocruz), Escola Nacional de Saúde Pública Sergio Arouca (Ensp), Departamento de Saneamento e Saúde Ambiental (DSSA) - Rio de Janeiro (RJ), Brasil. deboracyklig@gmail.com

4 Fundação Oswaldo Cruz (Fiocruz), Escola Nacional de Saúde Pública Sergio Arouca (Ensp), Departamento de Saneamento e Saúde Ambiental (DSSA) - Rio de Janeiro (RJ), Brasil. simoneccohen@gmail.com

\section{Possíveis contribuições da integração das políticas públicas brasileiras à redução de desastres}

\author{
Possible contributions of the integration of Brazilian public policies \\ for disaster reduction
}

Rafaela Facchetti Assumpção', Elida Séguin², Débora Cynamon Kligerman³, Simone Cynamon Cohen $\mathbf{4}$

RESUMO Neste artigo, faz-se uma análise documental da Política Nacional de Recursos Hídricos (Lei n ${ }^{\circ}$ 9.433/1997), da Política Federal de Saneamento (Lei $n^{\circ} 11.445 / 2007$ ), da Política Nacional de Defesa Civil (Lei $\left.{ }^{\circ} 12.608 / 2012\right)$ com o fim de verificar como a integração dessas políticas contribuiriam para a redução das fatalidades nesses desastres naturais. Observou-se que a legislação existente é bastante avançada, mas que o País carece da fiscalização no cumprimento destas para efetiva redução de fatalidades. Complementarmente, é necessária a criação de instâncias participativas e ações educativas.

PALAVRAS-CHAVE Saneamento básico. Drenagem. Legislação. Desastres.

ABSTRACT In this article, a documentary analysis of the National Water Resources Policy (Law no 9,433/1997), the Federal Sanitation Policy (Law no 11,445/2007), the National Civil Defense Policy (Law no 12,608/2012) was carried out to verify how the integration of those policies would contribute to the reduction of fatalities in such natural disasters. It was observed that the existing legislation is quite advanced, but the country lacks the supervision in the fulfillment of those laws to effectively reduce fatalities. Complementarily, it is necessary to create participatory instances and educational actions.

KEYWORDS Basic sanitation. Drainage. Legislation. Disasters. 


\section{Introdução}

Ao longo da história da humanidade, as inundações impactaram de maneira significativa os assentamentos humanos. A proximidade de rios sempre foi fator preponderante da lógica humana para escolha dos lugares de construção de habitações, facilitando o acesso aos meios necessários para a subsistência, inserindo na relação homem/natureza o componente simbólico da água como bem material e imaterial, ou seja, como fonte de sobrevivência e como elemento sagrado.

Ensinavam os antigos que todo bem pode trazer um mal, assim a proximidade dos mananciais também acarreta riscos que afetaram essas civilizações, como: as inundações, a salinização das áreas irrigadas, a proliferação de mosquitos, as doenças transmitidas por estes vetores e outras por via hídrica.

Discute-se, hoje, se as mudanças climáticas interferem, ou não, nos eventos extremos e se estas colaboram para o aumento da ocorrência e/ou agravo dos desastres em todo o planeta. No Brasil, inundações severas acompanhadas por deslizamentos de terra são os principais desastres registrados. Esses eventos precisam ser melhor avaliados, determinadas suas causas e elaboradas estratégias de resposta, no sentido de almejar um alto grau de resiliência.

As inundações são consequência da falta de políticas públicas. Dados do 'Caderno setorial de recursos hídricos' do Ministério do Meio Ambiente (MMA) indicam que

[...] dos 5.507 municípios brasileiros, 4.327 (79\%) dispõem de sistema de drenagem, sendo que, destes, $85 \%$ possuem rede subterrânea de drenagem. Mesmo que pareça elevado, dos municípios com sistema subterrâneo de drenagem, apenas $33 \%$ possuem estruturas de macrodrenagem. (BRASIL, 2006, P. 41-42).

Tucci (2005) alerta que as inundações estão se intensificando devido ao aumento do processo de urbanização desordenado, sem que haja um planejamento urbano acompanhado de infraestrutura de drenagem e manejo adequado das águas pluviais.

A ausência de saneamento básico adequado é fator agravante aos desastres naturais provocados por chuvas fortes, dado que poucas cidades possuem, no Brasil, um sistema eficiente. No entanto, observa-se que esses dados não aferem nem a qualidade nem o percentual da cobertura da rede de microdrenagem e macrodrenagem nesses municípios, a pesquisa feita para o Sistema Nacional de Informação sobre Saneamento (SNIS), referente ao ano de 2014 considerava apenas se existia, ou não, uma rede; não importando qual a sua extensão e eficiência. Os novos dados referentes à pesquisa de 2015 sobre águas pluviais estão sendo requeridos diretamente às prefeituras conforme informado no sítio http://www.snis.gov.br/ coleta-de-dados-snis-aguas-pluviais (SNIS, 2016), as prefeituras receberão um e-mail com as instruções de acessar um link e preencher os dados referentes à drenagem municipal, mas esses resultados obtidos somente serão publicados em 2017.

Desde a Constituição Federal de 1988, estava previsto, em seu art. 21, inciso XVIII, ser competência da União planejar e promover a defesa permanente contra as calamidades públicas, especialmente as secas e as inundações. Posteriormente, diversas leis ordinárias regulamentaram este artigo, entre elas as de $n^{\circ} 9.433 / 1997,11.445 / 2007$ e $12.608 / 2012$, mas, ainda, não foram suficientes para deter o número crescente de vítimas desses desastres.

Segundo Tucci e Bertoni (2007, P. 24), há "falta de decisão pública" e que quando essa é tomada, possui uma "visão de curto prazo", não havendo uma política de prevenção dentro de um plano de gestão de riscos de desastres. Em 2007, foi promulgada a Lei $\mathrm{n}^{\mathrm{o}}$ 11.445, que instituiu a Política Federal de Saneamento Básico. Ressalta-se que comumente a água potável, o esgotamento sanitário, a limpeza urbana e o manejo de resíduos sólidos são serviços públicos 
municipais concedidos, dos quais a cobrança foi absorvida pela população. Para que haja implementação da legislação vigente, deve haver controle social efetivo, e não apenas no papel. Acrescenta-se que a drenagem e o manejo das águas pluviais urbanas são serviços que não possuem a tradição de serem cobrados, recaindo os seus custos aos cofres municipais, sendo assim, a precariedade na prestação desses serviços é um fato.

A metodologia adotada neste artigo tem como base a pesquisa exploratória, sendo utilizado como procedimento técnico a pesquisa documental em três Políticas Públicas: Política Nacional de Recursos Hídricos (Lei $n^{0}$ 9.433/1997), Política Federal de Saneamento Básico (Lei no 11.445/2007) e Política Nacional de Proteção e Defesa Civil (Lei $\left.n^{0} 12.608 / 2012\right)$; partindo-se da hipótese que a integração, o cumprimento, o controle social e a fiscalização dessas políticas minimizariam as consequências de eventos extremos e preveniriam os pequenos desastres.

No presente artigo, buscou-se analisar, embora sem a pretensão de esgotar o tema, como as Leis $\mathrm{n}^{\circ} 11.445 / 2007,12.608 / 2012 \mathrm{e}$ outras políticas públicas podem contribuir para implementar ou melhorar o sistema de drenagem e para minimizar os desastres provocados por chuvas intensas e recorrentes.

\section{Drenagem e manejo das águas pluviais urbanas}

O conceito de drenagem urbana, "admite uma divisão em dois conjuntos de abrangência: a microdrenagem e a macrodrenagem" (CHAMPS, 2009, P. 335). Em que a primeira é composta pela captação dos escoamentos superficiais, a malha viária da cidade, sarjetas, caixas de captação e rede subterrânea e a segunda é constituída pelos "canais naturais e galerias por onde escoam os cursos d'água, como córregos, ribeirões e rios e de equipamentos urbanos para regularização de cheias" (CHAMPS, 2009, P. 335).

Os sistemas urbanos de drenagem devem comportar as águas de precipitações pequenas e médias, o que corresponde às chuvas com tempo de retorno de até 25 anos (CANHOLI, 2005). As grandes chuvas com tempo de retorno superior demandariam obras de custo altíssimo para atender a eventos extremos. Estes exigem uma abordagem adaptativa conjugada com medidas estruturais e não estruturais, como: Planos de Emergência, Contingência e Sistemas de Alerta que apresentam melhores resultados, com custo compensador, quando aliados à capacitação e ao treinamento da população.

Com as medidas estruturais e não estruturais, o sistema de drenagem, deveria evitar que toda a precipitação pluviométrica alcance a rede de macrodrenagem ao mesmo tempo. Vários municípios brasileiros adotam o sistema de reuso da água de chuva ou o de captação, retenção e liberação após um determinado tempo finda a chuva, popularmente denominado de 'piscininhas'.

Para obter maior sucesso na adoção de reservatórios de detenção de águas pluviais, é fundamental que sejam feitas campanhas que informem a população sobre a importância do aproveitamento das águas pluviais para fins não potáveis e como isso poderia diminuir o consumo de água potável para fins pouco nobres, como lavagem de pátios, regar jardins e outros, além da economia que promoveria em suas contas de água.

No Estado do Rio de Janeiro, a Assembleia Legislativa do Estado do Rio de Janeiro (Alerj), propôs o projeto de Lei ${ }^{0}$ 2.121/2009 que tornaria obrigatório a captação, o armazenamento e a utilização das águas pluviais nos edifícios urbanos, responsabilizando as empresas projetistas e de construção civil do estado a

[...] dispor de coletores, caixa de armazenamento e distribuidores para água da chuva nos projetos de empreendimentos residenciais que abriguem mais de 10 (dez) famílias ou nos de empreendimentos comerciais com mais que 500 m2 de área construída. (RIO DE JANEIRO, 2009). 
Esse projeto de lei foi arquivado sem aprovação (ALERJ, 2013). Já o Decreto nº 23.940/2004

torna obrigatório, nos casos previstos, a adoção de reservatórios que permitam o retardo do escoamento das águas pluviais para a rede de drenagem. (RIO DE JANEIRO, 2004).

Outros estados e municípios brasileiros adotaram leis semelhantes ou têm propostas em estudo.

\section{Da sinergia entre algumas políticas públicas}

Várias foram as tentativas legais de minorar a questão das inundações e desastres correlatos, equacionando problemas e estabelecendo diretrizes. Todavia, há necessidade de que as propostas sejam trabalhadas de forma integrada e sistêmica.

\section{a) Da Política Nacional de Recursos Hídricos (PNRH)}

A Política Nacional de Recursos Hídricos (PNRH) foi instituída pela Lei ${ }^{\circ}$ 9.433/1997, mas caminha a passos lentos, em especial a densificação e efetividade dos Comitês de Bacia, seja por falta de interesse dos entes públicos, seja por sua principal característica, a instância decisória, ser um colegiado tripartite do qual participam a sociedade civil, os usuários e o poder público das três esferas. As decisões demandam muitas reuniões, e há pouca eficiência por parte das Agências de Bacia, braços executivos, em contratar e apresentar projetos. A verba da cobrança pelo uso da água ainda é pequena, e os Comitês de Bacia têm pouca visibilidade. A mobilização para participação pode ser indicada como o 'calcanhar de Aquiles' dessa política.

$\mathrm{Na}$ esfera federal, a União publicou o Plano Nacional de Recursos Hídricos que serve como diretriz para os planos regionais e estaduais. Entretanto, no que tange ao controle de cheias, e especificamente à drenagem, esse plano pouco acrescenta, sendo anterior à edição da Lei $n^{\circ} 12.608 / 2012$, que instituiu a Política Nacional de Proteção e Defesa Civil não trazendo uma interface entre essas duas políticas. Espera-se que esta interface será contemplada na próxima revisão da lei.

\section{b) Da Política Federal de Saneamento Básico}

Chama a atenção que todas as outras políticas ambientais são nacionais, esta é federal, o que pode ser explicado pelo fato de a Constituição prever quatro entes federativos: União, Estados, Municípios e Distrito Federal. As leis procedentes da união podem ter aplicabilidade nacional, para todo o País, ou apenas federal: alcançam apenas a administração pública federal, como a Lei $n^{\text {o }}$ 9.784/1999, que disciplinou o processo administrativo. Quando a competência legislativa não é da união, ela pode emitir diretrizes gerais, sem entrar em detalhes, como a Lei $\mathrm{n}^{\circ}$ 6.766/1979 (Dispõe sobre o Parcelamento do Solo Urbano). Portanto, na Lei $n^{\circ} 11.445 / 2007$, cabe a quem detém a competência disciplinar, efetivamente, o assunto. As diretrizes federais não podem ser contrariadas pelos estados ou municípios, mas, também, elas não podem invadir a competência desses.

Aos estados e municípios, cabe elaborarem seus Planos Diretores de Saneamento Básico. Sua efetividade será maior se eles forem feitos de forma integrada com as demais políticas estaduais e municipais. A Lei $\mathrm{n}^{\mathrm{o}}$ 11.445/2007 ressalta, ainda, a importância de o Plano de Saneamento estar em conformidade com os Planos de Bacia Hidrográfica, indicando uma clara preocupação com a integração das políticas regionais.

O Ministério das Cidades, seguindo o preceituado pela Lei $n^{\circ} 9.433 / 1997$, que estabeleceu a PNRH, salientou a importância de optar por 
utilizar a bacia hidrográfica como unidade de planejamento [pois] possibilita uma visão não fragmentada das inter-relações do homem com o meio e deste consigo mesmo. Permite compreender como uma ação, em qualquer ponto da bacia, reflete no conjunto. (BRASIL, 2005, P. 68).

A percepção do poder público em relação à drenagem e ao manejo de águas pluviais, como componentes do saneamento básico e de preservação ambiental, ainda não foi bem compreendida, nem mesmo a oportunidade de cobrar por este serviço foi apreendida e posta em prática na maior parte dos municípios brasileiros. Espera-se que os novos Planos Municipais Diretores de Saneamento englobem todos os serviços e alterem as concessões de água e esgoto para água, esgoto e drenagem. Com certeza isto acarretará em mais um custo para a sociedade, mas este será certamente menor que os prejuízos das inundações e daqueles deslizamentos de terra evitáveis por drenagem adequada.

\section{C) Política Nacional de Proteção e Defesa Civil (PNPDEC)}

A Lei $n^{\circ}$ 12.608/2012 instituiu a Política Nacional de Proteção e Defesa Civil (PNPDEC); dispôs sobre o Sistema Nacional de Proteção e Defesa Civil (SINPDEC) e o Conselho Nacional de Proteção e Defesa Civil (CONPDEC); autorizou a criação de sistema de informações e monitoramento de desastres; alterou as Leis $n^{\circ} 12.340 / 2010$, 10.257/2001, 6.766/1979, 8.239/1991, e 9.394/1996; e deu outras providências.

Essa lei reconhece em seu art. 26, inciso IV, que um dos mais importantes componentes de prevenção de desastres em regiões dadas a movimentos de massa e inundações é a drenagem. São fatores que influenciam na decisão de implantar um sistema de drenagem: 1) meios legais e institucionais para uma política factível de drenagem urbana; 2) uma política de ocupação das várzeas de inundação, que não entre em conflito com essa política de drenagem urbana; 3) recursos financeiros e meios técnicos que sustentem essa política; 4) domínio das tecnologias necessárias e mão de obra qualificada para sua implantação; 5) entidades capazes de desenvolver as atividades de comunicação social e promover a participação coletiva; 6) organismos que possam estabelecer critérios e aplicar leis e normas com relação ao setor e 7) opinião pública.

A edição dessa lei supre uma lacuna mencionada, apesar de já existirem outros diplomas legais vigentes que tratavam da matéria. Ela constitui um marco regulatório para a prevenção de desastres no Brasil.

Essa lei foi editada quando o País ainda estava sob o impacto emocional do desastre da Região Serrana do Estado do Rio de Janeiro; supre uma lacuna, porém não será suficiente para alcançar o objetivo colimado de segurança civil se não for acompanhada de ações efetivas. Para Séguin (2013, P. 212) a

legislação, ao impor diretrizes comportamentais tais como a capacitação dos agentes públicos, o acesso à informação e a participação da comunidade, atua como fonte de prevenção de desastres, de rapidez na resposta pública no gerenciamento de crise.

A PNPDEC deverá trabalhar a sinergia que caracteriza as relações ambientais, em uma visão transdisciplinar incentivando o ensino e a pesquisa que deve embasar uma tomada de decisão que pode vir a ser a diferença entre vida e morte. A PNPDEC segundo Séguin (2013, P. 216),

[...] abrange as ações de prevenção, mitigação, preparação, resposta e recuperação voltadas à proteção e defesa civil, devendo buscar a integração com as políticas de ordenamento territorial, desenvolvimento urbano, saúde, meio ambiente, mudanças climáticas, gestão de recursos hídricos, geologia, infraestrutura, educação, ciência e tecnologia e às demais políticas setoriais, tendo em vista 
a promoção do desenvolvimento sustentável.

Outro avanço proposto por essa lei foi o cadastro nacional de áreas suscetíveis à ocorrência de deslizamentos de grande impacto, inundações bruscas ou processos geológicos ou hidrológicos correlatos, que deverá ser composto pelas informações de todos os municípios brasileiros (art. 22). As autoras desse artigo criticam a falta de prazo para que os municípios façam a inscrição neste cadastro e forneçam as informações necessárias para compô-lo.

De acordo com análise de Séguin (2013, P. 218), a PNPDEC é "coerente com o Princípio da Precaução, posto que planejar é a melhor forma de reduzir riscos" e impõe

[...] a elaboração de um Plano Nacional de Proteção e Defesa Civil, que deverá conter, no mínimo: a identificação dos riscos de desastres nas regiões geográficas e grandes bacias hidrográficas do País; e as diretrizes de ação governamental de proteção e defesa civil no âmbito nacional e regional, em especial quanto à rede de monitoramento meteorológico, hidrológico e geológico e dos riscos biológicos, nucleares e químicos e à produção de alertas antecipados das regiões com risco de desastres. (SÉGUIN, 2013, P. 218).

Este apresentará aspectos regionais que individualizarão o plano estadual e municipal, determinando seus conteúdos específicos, respeitando as características físicas, sociais, culturais e ambientais do local.

A PNPDEC abrange as ações de prevenção, mitigação, preparação, resposta e recuperação voltadas à proteção e defesa civil, integrando-se às políticas de ordenamento territorial, desenvolvimento urbano, saúde, meio ambiente, mudanças climáticas, gestão de recursos hídricos, geologia, infraestrutura, educação, ciência e tecnologia e às demais políticas setoriais, tendo em vista a promoção do desenvolvimento sustentável. Assim, o princípio da Economicidade, previsto no art. 70 da Constituição Federal, que veda a duplicidade de meios para atingir a uma única finalidade, deve ser aliado ao princípio da Cooperação entre os entes federativos (art. $4^{\circ}$, inciso I da PNPDC).

Em áreas densamente povoadas, os desastres naturais ganham maiores proporções, com o tributo de vidas humanas, além dos danos materiais. Os sistemas jurídico e legislativo brasileiro engatinham na seara da prevenção, preparados parcialmente apenas para discutir responsabilidades civis, penais e administrativas dos desastres. Diz-se parcialmente, pois, apesar da previsão legislativa, pouco se condenam os agentes públicos por prevaricação ou são responsabilizados pelas omissões estatais que deram origem, estas sempre subjetivas e não mais objetivas na forma do art. $37 \mathrm{da}$ Constituição Federal de 1988.

O dano das catástrofes é quase sempre causado, ou no mínimo agravado, pela falta de regulação antecipada de riscos pelo direito fundiário e pelo direito ambiental. A ocupação humana desordenada potencializa os efeitos dos desastres naturais. Respeitar as limitações naturais de habitabilidade e restringir as ocupações às áreas de risco são decisões municipais que devem ser adotadas para evitar a gravidade dos desastres, em especial por estar vinculada à fragilidade do ambiente socialmente construído e na vulnerabilidade de seus habitantes.

\section{d) Do uso, parcelamento e ocupação do solo: o Estatuto da Cidade}

Em complementação, acrescenta-se que a ocupação do solo, urbano ou rural, para qualquer tipo de atividade possui relação direta com as inundações. A primeira regulamentação do parcelamento do solo foi o Decreto-Lei no 58/1937, em uma visão de proteção individual e garantia das relações jurídicas. Este dispositivo legal ainda está vigente para áreas rurais, sendo a divisão do solo urbano regulamentado pela Lei $\mathrm{n}^{\mathrm{o}}$ 6.766/1979, que introduziu novos conceitos 
como a faculdade de o parcelador do solo estabelecer restrições urbanísticas, que o projeto atenda a requisitos urbanísticos (art. $4^{\circ}$ ), a obrigação de o parcelador dotar o local de infraestrutura básica ( $\$ 6^{\circ}$ do art. $2^{\circ}$ ) e a coerência entre o plano apresentado e o Plano Diretor (art. $3^{\circ}$ ), estabelecendo uma parceria público/privado, entre outras coisas (SÉGUIN, 2013). A humanidade, para suprir suas necessidades básicas de habitar, trabalhar e circular, transformou a atividade edilícia em inimiga da segurança civil. O uso do solo e a especulação imobiliária são identificados como os grandes vilões dos desastres hidrológicos, como se inexistissem Políticas Públicas e Ações Governamentais preventivas de desastres. Conforme pontua Séguin (2013), estes não são os únicos a errarem por ação ou por omissão. Há um pacto do silêncio, entre comunidade e poder municipal, com várias modalidades de participação.

Ressalta-se que, em seu art. 23, a PNPDEC proíbe a concessão de licença ou alvará de construção em áreas de risco indicadas como não edificáveis no plano diretor ou legislação dele derivada. No entanto, sabe-se que a maior parte das construções em áreas de risco não passa pelo licenciamento e nem mesmo há uma preocupação com a sua legalização, dado que a maior parte não tem sequer a posse do terreno, que é oriundo de invasão ou grilagem (SÉGUIN, 2013). O problema fundiário nos municípios vai de encontro à segurança dos moradores. Atualmente, poucos são os terrenos em áreas urbanas próximas ao mercado de trabalho em condições de edificação, as que existem possuem um valor altíssimo no mercado imobiliário. Assim, a população menos privilegiada se obriga a morar longe ou se arrisca ao morar em áreas de risco.

Ao contrariar a lógica de erro e punição, a PNPDEC adota, conforme observa Séguin (2013, P. 227),

[...] a técnica de estímulos positivos e [...] prevê que a União pode conceder incentivo ao município que aumentar a oferta de terra urbanizada para utilização em habitação de interesse social, por meio dos institutos previstos no Estatuto da Cidade, transferindo recursos para a aquisição destes terrenos. (art. 16).

Séguin (2013, P. 227) afirma, ainda, que

[...] apesar da expressa previsão na PNPDEC que os programas habitacionais devem priorizar a realocação de comunidades atingidas e de moradores de áreas de risco, a remoção é um problema sério posto que as pessoas, mesmo reconhecendo o risco, em geral, se recusam a sair.

Para essa autora, muitos são os motivos dessa recusa, 'aparentemente incompreensível', mas ao se observar com mais acurácia, entende-se a desconfiança que permeia as comunidades em áreas de risco, dado que muitos, ao abandonar suas casas, têm os seus pertences saqueados, mesmo durante a ocorrência do desastre. Outra insegurança identificada é não haver um prazo para que ocorra a realocação, pois não existem unidades habitacionais prontas para servir a este fim, o que em muitos casos perpetua o aluguel social.

Com relação ao uso e parcelamento do solo, a PNPDEC incluiu os arts. 42A e 42B no Estatuto da Cidade para adequá-lo, e estes determinam que o Plano Diretor de Municípios, com áreas de risco, explicitem: I - parâmetros de parcelamento, uso e ocupação do solo, de modo a promover a diversidade de usos e a contribuir para a geração de emprego e renda; II - mapeamento contendo as áreas suscetíveis à ocorrência de deslizamentos de grande impacto, inundações bruscas ou processos geológicos ou hidrológicos correlatos; III - planejamento de ações de intervenção preventiva e realocação de população de áreas de risco de desastre; IV - medidas de drenagem urbana necessárias à prevenção e à mitigação de impactos de desastres; e V - diretrizes para a regularização 
fundiária de assentamentos urbanos irregu-

lares, se houver.

Constata-se que há uma preocupação da PNPDEC com a crise habitacional que induz as pessoas a fazerem suas casas em áreas de risco e que esta pretende contribuir para inibir tal prática. Contudo, salienta-se que a legislação parece ignorar as técnicas adaptativas que podem ser soluções de menor custo e menos traumáticas para as populações em áreas de risco.

\section{Da política das tragédias}

As inundações são consequência de um aumento do volume de água nos leitos dos rios, riachos, lagos, lagoas etc., provocados por chuvas intensas. As causas básicas de inundações são reconhecidas pela literatura técnica que as correlacionam com a ocupação do solo desordenada ou não, que impermeabiliza e induz: ao aumento dos escoamentos superficiais, ao assoreamento dos rios e as alterações dos cursos com estreitamentos, pontes e demais intervenções. Tanto o meio urbano quanto o rural contribuem com constantes desmatamentos, dificultando a retenção das águas no solo e alterando drasticamente o hidrograma de cheia da região (TUCCl; BERTONI, 2007).

A prevenção de inundações demanda um sistema de drenagem eficiente e um manejo de águas pluviais adequado, planejado de acordo com as características de cada município. Relatos da Defesa Civil reconhecem que a falta de uma drenagem adequada leva a desastres que poderiam ser evitados. A falta de tratamento de esgotos domésticos, bem como o lançamento de lixo nos rios, gera doenças de veiculação hídrica que se manifestam quando de grandes inundações.

Com a promulgação da PNPDC, espera-se que os poderes municipais se alinhem com as políticas de prevenção de desastres e utilizem suas verbas e a força do executivo para contribuir na prevenção, para que não sejam mais necessárias as verbas emergenciais.
Cabe à população se mobilizar para cobrar essas providências, seja diretamente do poder público e/ou com a participação nos comitês de bacia.

Complementando esta análise das políticas, comenta-se que, no quesito acesso à informação, devem ser consideradas

a evolução e a importância de recursos midiáticos na divulgação, controle e comunicação de desastres, como demonstrado no trabalho, apresentado por Cardoso, Bolsoni e Souza (2009), sob o título: 'O Twitter e suas potencialidades como ferramenta de comunicação em ambientes acometidos por desastres', uma vez que as potencialidades do ciberespaço perpassam por quase todos os setores da sociedade. O computador gera novas formas de sociabilidade, podendo ser uma importante ferramenta de comunicação em caso de desastres. (SEGUIN, 2013, P. 217).

Esses meios já estão sendo utilizados, embora de forma pouco integrada pelos atuais sistemas de alerta de chuvas, utilizando o MSN e e-mails, no entanto, em algumas localidades, a cobertura para celulares é precária, recomendando que se avance mais em estudar como ampliar a rede de informações, talvez pela implantação de um conjunto de rádios que ficariam com pessoas chave em cada comunidade.

\section{Conclusões}

Do ponto de vista histórico, a construção de valores representativos da relação homem/ natureza implica questionamentos e elaboração de ações no sentido da utilização do potencial oferecido pelo ambiente. Em termos da realidade contemporânea, a questão ambiental se configura como contexto que impõe profundas reflexões sobre essa relação. Observa-se ainda que essa se expressa, sobretudo, na dimensão social, não sendo, portanto, de caráter unicamente ecológico, pois a crise ambiental apresenta 
sinais claros dos dilemas dos valores consolidados pela sociedade de consumo.

Destaca-se que os desastres naturais, na maior parte dos casos, não são eventos completamente fora do controle nem são acidentes inevitáveis, ou seja, fora do controle humano. A capacidade de planejar, antecipando acontecimentos, pode diminuir a probabilidade dos desastres e reduzir seus danos, bem como estabelecer procedimentos para a reconstrução, após a ocorrência, garantindo uma resposta rápida e eficiente no socorro das vítimas. O sistema jurídico desempenha um papel central na prevenção de desastres, resposta e gerenciamento, mas deverá operar com os técnicos e com a população envolvida para obter melhores resultados.

Reconhece-se que houve um grande avanço com a Lei $n^{\circ} 11.445 / 2007$, mas os municípios necessitam viabilizar este sistema financeiramente, os sistemas de drenagem urbana, dado que água, esgoto e resíduos sólidos já são cobrados.

Uma possível solução para viabilizar financeiramente a drenagem nos municípios seria a condução das águas de drenagem para uma estação de tratamento independente, pertencente à concessionária de água e esgoto, para que essas águas fossem tratadas e potabilizadas, ou fornecidas com tratamento especial para indústrias. Isso seria uma forma para que aqueles municípios com problemas de inundação e/ou escassez de água se beneficiem com as águas pluviais. Outra possibilidade é a condução dessas águas para alguma represa de geração de energia hidroelétrica.

O custo dos serviços de drenagem poderia também ser parte de uma contrapartida dos municípios para o recebimento do Imposto sobre Circulação de Mercadorias e Serviços (ICMS) verde, ou buscar formas para que as concessionárias de água e esgoto aceitassem fazer a drenagem e o manejo em troca do aproveitamento dessas águas sem o custo da cobrança pelo uso da água e que tivessem um desconto no pagamento do Imposto Sobre Serviço (ISS).
A nova política de Defesa Civil muda a compreensão dos desastres, apresentado um grande potencial para preveni-los e não atuar apenas como socorrista, contribuindo para o desenvolvimento e segurança social, agindo no combate das vulnerabilidades socioeconômicas, ambientais e políticas públicas, com atitudes proativas. Ademais, para conviver com os desastres naturais, é imprescindível entender e conceituar cada fenômeno, verificando quais as medidas preventivas que devem ser realizadas antes, durante e depois de sua ocorrência.

Essa vulnerabilidade da população que convive com os riscos socioambientais é traduzida pela impressa e pelos discursos políticos, como vinculada a negligência do poder público diante do próprio risco e suas consequências mais imediatas, ou seja, a situação dramática dos desabrigados ou desalojados, vítimas das chuvas. A imprensa também veicula a ideia de que há uma 'indústria das enchentes', que se baseia no aumento do fluxo de verbas a fundo perdido para os cofres municipais quando da ocorrência de tais eventos. São frequentes as denúncias de que essas verbas são manipuladas na execução de obras emergenciais e que, portanto, não passam por rigorosas licitações e nem por um crivo técnico que faça uma avaliação tanto de sua necessidade como de sua eficiência.

A literatura sobre o tema aponta que em termos de proposição técnica, o que poderia ser útil ao município seriam as medidas combinadas de manejo que associado a obras convencionais e a proposições alternativas, como reservatórios no próprio lote, pequenas bacias de contenção nos afluentes dos rios que cortam a cidade, entre outras, mas principalmente, a gestão integrada das políticas públicas (CANHOL, 2005). Por outro lado, constata-se que a organização popular é ainda incipiente, especialmente no que se refere ao exercício pleno do seu direito de controle e participação, que preconiza a Lei $n^{\circ} 11.445 / 2007$. A insuficiente participação da sociedade está vinculada às limitações da educação 
participativa voltada para consolidação da cidadania, sendo esta indispensável para efetiva participação nas decisões de gestão.

Uma resposta a esse questionamento pode ser uma maior mobilização dos Comitês de Bacia Hidrográfica, promovendo uma maior participação nos processos decisórios. Outra forma de participação é durante as consultas públicas para a elaboração dos Planos Diretores Urbanos. Nestes deve haver a integração dos Planos Municipais de Saneamento Básico e dos de Gerenciamento de Resíduos Sólidos, aos Planos de Bacia
Hidrográfica, com isto possibilitando uma Gestão Integrada das Águas e do Território.

Reafirma-se estar diante de um problema complexo e que sua solução depende da articulação das diferentes políticas públicas. A prevenção da ocorrência de desastres com inundações somente acontecerá quando a política de planejamento urbano estiver integrada com as demais políticas, como a de saneamento ambiental, a de recursos hídricos e a de defesa civil, e quando houver a efetiva participação popular, exercendo o seu direito ao controle social.

\section{Referências}

BRASIL. Lei no 6.766, de 19 de dezembro de 1979.

Dispõe sobre o Parcelamento do Solo Urbano. Diário

Oficial [da] União, Brasília, DF, 19 dez. 1979. Disponível em: <http://www.planalto.gov.br/ccivil_03/leis/L6766. htm>. Acesso em: 6 ago. 2016.

Lei $n^{\circ} 9.433$, de 8 de janeiro de 1997. Institui a

Política Nacional de Recursos Hídricos, cria o Sistema Nacional de Gerenciamento de Recursos Hídricos.

Diário Oficial [da] União, Brasília, DF, 8 jan. 1997. Disponível em: <http://www.planalto.gov.br/ccivil_03/ leis/L9433.htm>. Acesso em: 6 ago. 2016.

Lei ${ }^{\circ} 11.445$, de 5 de janeiro de 2007. Estabelece diretrizes nacionais para o saneamento básico. Diário Oficial [da] União, Brasília, DF, 5 jan. 2007. Disponível em: <http://www.planalto.gov.br/ccivil_03/_ato20072010/2007/lei/111445.htm>. Acesso em: 6 ago. 2016. a Política Nacional de Proteção e Defesa Civil. Diário Oficial [da] União, Brasília, DF, 10 abr. 2012. Disponível em: <http://www.planalto.gov.br/ccivil_03/_ato20112014/2012/lei/112608.htm>. Acesso em: 6 ago. 2016.

Ministério das Cidades. Organização PanAmericana da Saúde. Política e Plano Municipal de Saneamento Ambiental: experiências e recomendações. Brasília, DF: OPAS, 2005.

Ministério das Cidades. Secretaria Nacional de Saneamento Ambiental. Programa de Modernização do Setor Saneamento. Instrumentos das políticas e da gestão dos serviços públicos de saneamento básico. Brasília, DF: Editora, 2009.

Ministério do Meio Ambiente. Secretaria de Recursos Hídricos. Caderno setorial de recursos hídricos: saneamento. Brasília, DF: MMA, 2006. 
CANHOLI, A. P. Drenagem Urbana e Controle de inundações. São Paulo: Oficina de Textos, 2005.

CARDOSO, C.; BOLSONI, E. P.; SOUZA, C. H. M. O

Twitter e suas potencialidades como ferramenta de comunicação em ambientes acometidos por desastres. In: SEMINÁRIO INTERNACIONAL DE DEFESA CIVIL, 5, 2009, São Paulo. Anais... Florianópolis: UFSC, 2009. Disponível em: <http://www.ceped.ufsc.br/wp-content/uploads/2009/01/Artigo-13.pdf >. Acesso em: 20 maio 2016.

CHAMPS, J. R. Manejo de águas pluviais urbanas: o desafio da integração e da sustentabilidade. In: BRASIL. Ministério das Cidades. Secretaria Nacional de saneamento ambiental. Programa de Modernização do Setor Saneamento. Instrumentos das políticas e da gestão dos serviços públicos de saneamento básico. Brasília, DF: Editora, 2009.

RIO DE JANEIRO (Estado). Decreto no 23.940, de 30 de janeiro de 2004. Torna obrigatório, nos casos previstos, a adoção de reservatórios que permitam o retardo do escoamento das águas pluviais para a rede de drenagem. Diário Oficial do Município, Rio de Janeiro, 30 jan. 2004.

Projeto de Lei n ${ }^{0}$ 2.121/2009 de 26 de março de 2009. Assembleia Legislativa do Estado do Rio de Janeiro, Rio de Janeiro, 26 mar. 2009. Disponível em: $<$ http://alerjln1.alerj.rj.gov.br/scpro0711.nsf/012cfeflf 272c0ec832566ec0018d831/84d9104d688c567683257

583005a544e? OpenDocument>. Acesso em: 6 jun. 2013.

SÉGUIN, E. A Lei de Defesa Civil: algumas considerações. Revista de Direito Ambiental, São Paulo, n. 34, v. 9. abr./jun. 2013. Disponível em: <http://faa.edu.br/ revistas/docs/RID/2012/RID_2012_14.pdf>. Acesso em: 6 ago. 2016.

\section{SISTEMA NACIONAL DE INFORMAÇÕES SOBRE} SANEAMENTO (SNIS). Coleta de dados do SNIS: águas pluviais. 2016. Disponível em: <http://www.snis.gov.br/ coleta-de-dados-snis-aguas-pluviais $>$. Acesso em: 15 dez. 2016.

TUCCI, C. E. M. Gestão das inundações urbanas. Brasília, DF: Global Water Partnership, 2005. Disponível em: <file://C:/Users/Ceb/Desktop/ Mariana/gestaodeaguaspluviais.pdf $>$. Acesso em: 6 ago. 2016.

TUCCI, C. E. M.; BERTONI, J. A. (Org.). Inundações Urbanas. Porto Alegre: ABRH/RHAMA, 2007.

Disponível em: <http://www.cepal.org/samtac/noticias/documentosdetrabajo/5/23335/inbr02803.pdf>. Acesso em: 6 ago. 2016.

Recebido para publicação em agosto de 2016

Versão final em dezembro de 2016

Conflito de interesses: inexistente.

Suporte financeiro: não houve. 